\title{
The MacGyver bias and attraction of homemade devices in healthcare
}

\author{
Laura V. Duggan, MD, FRCPC (1) - Stuart D. Marshall, MBChB, FANZA, PhD $\cdot$ Jeanette Scott, MB, FANZA • \\ Peter G. Brindley, MD, FRCPC • Hilary P. Grocott, MD, FRCPC
}

Received: 5 March 2019/Revised: 11 March 2019/Accepted: 19 March 2019/Published online: 12 April 2019

(C) Canadian Anesthesiologists' Society 2019

Angus "Mac" MacGyver is arguably one of the most famous fictional characters in modern pop culture. In the original television series (that aired from 1985 to 1992), MacGyver routinely overcame seemingly insoluble problems under time pressure with nothing more than readily available items (e.g., a Swiss Army knife, paper clip, and a chewing gum wrapper), common sense, and scientific acumen. This think-on-your-feet approach has held such a decades-long widespread appeal that "MacGyver" has become part of the modern vernacular, including its entry as a verb into the Oxford English Dictionary: "To make or repair (an object) in an improvised or inventive manner, making use of whatever items are at hand." 1

There are many healthcare-related examples of "MacGyvering" whereby immediately available equipment is combined or fashioned (in whole or in part) to substitute for equipment that is either unavailable or non-functional. Despite the potential positive aspects to MacGyvering equipment, we would like to suggest that patient-care could still be advanced by conscious understanding of the potential negative aspects as well. Indeed, we would like to propose the term "MacGyver

L. V. Duggan, MD, FRCPC $(\bowtie)$

University of British Columbia, Vancouver, BC, Canada

e-mail: lauravduggan@gmail.com

S. D. Marshall, MBChB, FANZA, PhD

Monash University, Clayton, VIC, Australia

J. Scott, MB, FANZA

Counties Manukau Health and Auckland District Health Board,

Auckland, New Zealand

P. G. Brindley, MD, FRCPC

University of Alberta, Edmonton, AB, Canada

H. P. Grocott, MD, FRCPC

Univesity of Manitoba, Winnipeg, MB, Canada bias" to describe the inherent attraction of our own personal improvised (MacGyvered) devices, with the tendency to hold them in high regard despite the relative absence of evidence for their efficacy.

Regardless of geographic location, profession, or specialty, healthcare providers appear to be aficionados of MacGyvered equipment, and workarounds in general. If "necessity is the mother of invention", healthcare may be the birthplace of workarounds. Individuals that write procedures or design equipment are often divorced from the reality of implementing it within the context that it is designed to be used in. Even when testing of equipment and procedures occurs before full clinical introduction, it often occurs in a laboratory setting or under ideal circumstances, and not in clinical, naturalistic settings. ${ }^{2}$ Consequently, clinicians are often faced with the need to find new ways to perform the work that are more efficient and better attuned to their work context.

\section{The value of MacGyvering}

On a positive note, MacGyvered workarounds with medical equipment can give insight into deficits of equipment or design. Anesthesiologists have a proud and robust history of inventing solutions to clinical problems. For example, in the Spanish Civil War, anesthesiologist Sir Robert Macintosh constructed a simple Flagg can-style ether vaporizer by "passing an endotracheal tube and attaching it to an ordinary tin (such as a container for motor oil) in the top of which two or three holes had been bored". ${ }^{3}$ Sir Robert Macintosh not only went on to design the Macintosh laryngoscope blade but also modified the design of life jackets during World War II to save the lives of unconscious soldiers. ${ }^{4}$ The original Laryngeal Mask Airway (LMA@), patiently designed and tested over many iterations, was invented by Sir Archie Brain. ${ }^{5}$ Through his determination and ingenuity, Sir Archie Brain did not simply "MacGyver" equipment on 


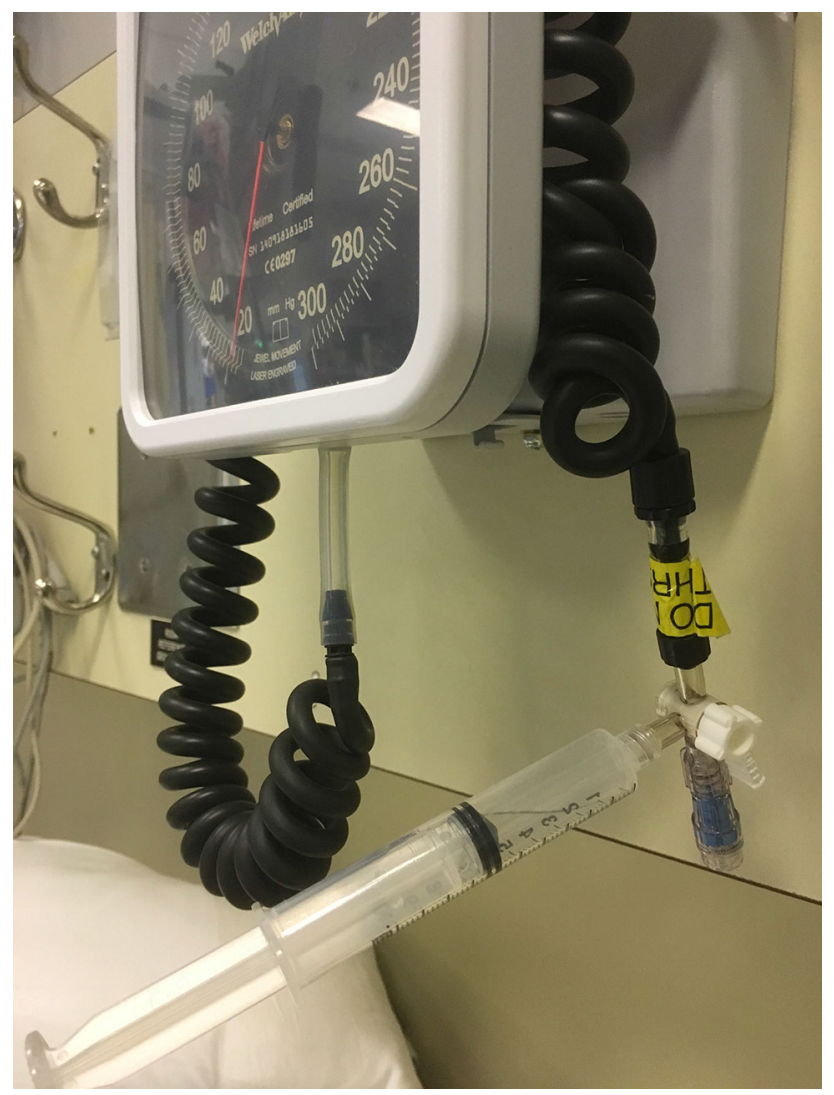

Figure MacGyvered equipment for measuring endotracheal tube cuff pressure fashioned from a three-way stopcock, a $10 \mathrm{~mL}$ syringe, and a blood pressure manometer. Given the wide scale of this blood pressure device, and its units in millimeters of mercury and not centimeters of water, accuracy of cuff pressures cannot be guaranteed. Commercial manometers for endotracheal tube cuff pressures are available

a local scale, but produced a commercially viable device for widespread distribution, and in doing so, has arguably saved more lives in modern anesthesia practice than any other person. Dr. Brain is an extreme, but perhaps not atypical, example of the clinician as inventor, with the LMA being the thirteenth patent that he had registered in his career. Interestingly, Dr. Brain built the LMA using a number of concepts, including the Leech airway, ${ }^{6}$ referenced in his LMA patent application. Without the Leech airway also being commercially available, Sir Archie Brain perhaps would not have had access to it as a precursor to assist in the development of the LMA.

\section{The unknowns of MacGyvering}

For a myriad of reasons, we are currently faced with, and grown accustomed to, equipment and medications being intermittently or permanently unavailable. Changes in expense, manufacturing, arduous approval protocols, and (ironically) either too frequent or too infrequent use of equipment may lead to sporadic availability. Even if stocked, if equipment is in an inconvenient location with respect to work flow patterns or cannot be readily found, healthcare workers will often create a workaround. For example, an individual may opt to use an endotracheal introducer with a coude tip for tube exchange if the fit-forpurpose airway exchange catheter is less conveniently stored outside of the operating room. Indeed, we may become so used to not having task-specific equipment available, that we may no longer notice the MacGyvered equipment we have used as a substitute is actually a workaround (Figure).

Healthcare professionals create and modify devices not only because equipment simply does not exist, but more commonly because access to commercially available equipment is lacking. The higher the life-threatening stakes, the more cognitive discomfort may arise from not having an accessible solution. New technologies, such as the videolaryngoscope, are marketed at considerable cost. One clinician-inventor's cognitive discomfort from not having ready access to this improvement in clinical care was relieved by jury-rigging a "poor man's" version from items purchased in the local electronic store. ${ }^{7}$ The solution is recognized as being clever, immediate, and cheap, and for the clinician-inventor may produce both an immediate emotional connection and cognitive relief. ${ }^{8}$ The effectiveness of this equipment has yet to be determined. ${ }^{9}$

As a broader public health example, postpartum hemorrhage is a leading cause of maternal mortality in low- and middle-income countries (LMIC), yet the cost (\$400 CAD) of a commercially available intrauterine balloon used for intrauterine tamponade may make it inaccessible. Nevertheless, a MacGyvered solution (creating an intrauterine balloon from Home Depot $($ ) equipment ${ }^{10}$ ) could potentially save women's lives in LMICs where no reasonable option previously existed. The effectiveness of this equipment has yet to be determined.

\section{The hazards of MacGyvering}

MacGyvered equipment may well provide a temporary solution to a problem, but because this solution has not been sufficiently examined, it might not work in all circumstances and may present additional unintended consequences of its use. Commercially available products must meet the standards required by regulatory authorities. A proprietary device should perform the intended function adequately and with a low failure rate and low harm rate in the hands of trained users. In some cases, thousands of tests may be required to ensure that fatigue or manufacturing flaws do not lead to dangerous conditions. Factory 
production lines have ongoing quality control measures to ensure that products do not vary from their intended form and function. Such quality control enables any clinical studies that follow to test a very specific device. In contrast, a MacGyvered solution has not been sufficiently studied, and the effectiveness, safety, and limitations of its clinical use are not well defined nor quality assured.

When commercial equipment that has been established to be safe for its original use is MacGyvered in novel ways ${ }^{11}$ the assurance that it will continue to both operate successfully and be safe for the patient cannot be guaranteed. ${ }^{12}$ Additional stresses and design flaws may manifest that were not observed when the device was used for its intended purpose.

In a systematic review of transtracheal jet ventilation in the "can't intubate can't oxygenate" (CICO) airway emergency, ${ }^{13}$ the authors found 42 correspondence letters in various journals suggesting a variety of equipment combinations for use during this life-threatening emergency situation, including dialysis catheters and nasogastric tubes; most publications also included the use of at least one three-way stopcock. None of these letters provided any evidence of effectiveness, yet all were published as a potential solution to the rare CICO emergency wherein the first attempt at emergency front of neck access (eFONA) may be the patient's best chance of survival. ${ }^{14,15}$

In addition, none added any evidence that these unproven homemade suggestions may potentially cause patient harm through device confusion, time taken to assemble equipment, ${ }^{16}$ paralysis of choice, ${ }^{17}$ and function failure. ${ }^{18}$ If a clinician uses such a suggestion, he or she may avoid publishing the result if the equipment does not work and may be more motivated to report it if the equipment succeeds (or vice versa); either way, publication bias will likely be at play as not all clinicians will be motivated to publish at all. In the systematic review above, ${ }^{13}$ of the various equipment combinations actually used in CICO emergencies, 38 of 90 cases (42\%) reported equipment failure, including bursting or fracturing of components with use, often with associated patient harm (e.g., fracturing of intravenous catheters leading to massive subcutaneous emphysema and inability to discern neck landmarks for further eFONA attempts). As Frerk ${ }^{19}$ noted, "no one would expect a pilot to learn how to make an emergency landing in an aeroplane made out of cardboard boxes while their colleague pretended to be air traffic control."

\section{Managing our own MacGyver bias}

Implicit to the impressiveness of MacGyver's accomplishments was always his ability to problem solve in high stake situations that could not be reasonably foreseen, under duress of severe resource constraints and time pressure. If the scenario can be foreseen, does not have strict resource constraints, or time pressure, is juryrigging in high risk situations justifiable? If MacGyver had known he might be abseiling that day, one might assume that he would have taken with him a modestly priced but purpose-designed solid metal carabiner, if not several. Are the resource constraints that produce MacGyverisms in our institutions always necessary, or are they sometimes the result of poor planning, poor workplace design, or funding biases? If necessity is the mother of invention, in modern medical practice we must be clear that the "necessity" exists.

We do not wish to imply that if devices are commercially available, they have, by definition, always been shown to be safe and efficient. In Canada, medical devices are regulated by the Medical Devices Bureau of the Therapeutic Products Directorate, "the national authority that monitors and evaluates the safety, effectiveness, and quality of diagnostic and therapeutic medical devices in Canada". ${ }^{20}$ Moreover, not all medical devices require a license to be sold in Canada, and there is controversy as to whether the licensing process for medical devices is adequate to ensure patient safety. ${ }^{21}$ Nevertheless, by having medical equipment commercially available, the safety of such equipment can be assessed by those not involved in the manufacturing process, whereas MacGyvered solutions cannot. It is noteworthy that "offlabel" prescription medicine use has a recognized code of conduct. Off-label drug prescriptions are only considered when there is sufficient published evidence or experience to assume safety and efficacy, when no suitably licensed medicine is available, or when the drug is part of a clinical research study. We believe that medical equipment should not, and need not, be different.

There is no doubt that a chance to showcase some creativity is enjoyable. It is fun to solve a problem, facilitate timely operating room list turnover without being "difficult", and be recognized by the theatre team as being creative and resourceful. The danger is that a workaround is so culturally appealing that it circumvents the level of scientific scrutiny that we would expect from any other equipment that we use. Novelty, immediacy, ownership, and ease of use can increase our propensity to bias and willful blindness. From a human factors perspective, the domain called "affective design" seeks to determine the emotional response of the user to designs. Users are more likely to stick with imperfect devices and explore their 
functions more fully if they are emotionally connected to them when they are used. ${ }^{8}$ Clinicians may become emotionally attached to their own inventions, equipment permutations, and ideas, which can become a source of identity and pride. ${ }^{22}$ We believe MacGyvered solutions appear to engender emotional connections in clinicians that marvel at their ingenuity above the tested designs of commercial products.

Inter-individual variation exists in clinical judgement, recognition of risk and degree of risk aversiveness. A decades-old case report describing a MacGyvered "poor man's LMA" received a swift letter in reply admonishing the "scant regard for caution", listing potential lethal consequences of the jury-rigged device and states that "there is a good case for stating that [an LMA] should have been available." One person's perceived success is another person's "potentially dangerous manoeuvre from which the patient and the author are fortunate to have emerged without an adverse outcome." 10,11 When no evidencedbased $^{18}$ commercially produced alternatives exist, there may be no choice. Nevertheless, we believe that this situation is now rapidly becoming a rarity. We suggest that creating idiosyncratic equipment is more likely to increase (not decrease) complexity and risk.

Perhaps the first step in tempering our immediate "intuition over evidence" acceptance and celebration of MacGyvered equipment in clinical situations is to identify and report instances when the clinical environment and equipment are suboptimal, and how this affects decisionmaking and clinical actions. A recent article ${ }^{23}$ investigated the risk tolerance of anesthesia trainees and consultants by posing 11 different clinical scenarios. Participants had to declare "go or no go" regarding whether to proceed with a patient's surgery based on the unavailability of certain equipment or wider hospital support (e.g., lack of waveform capnography or lack of an intensive care unit bed). Answers varied widely, with consultants more likely to proceed with surgery despite the lack of essential equipment defined by regulatory minimum standards. Although national guidelines exist regarding essential equipment for anesthesia care $^{24}$ the concept of "acceptable risk" is not well defined.

In conclusion, we would like to coin the term "MacGyver bias" to alert clinicians to their potential bias of holding homemade devices to a lesser evidence-based standard than commercially made devices, in part, due to our positive emotional responses to our own creations. We wish to highlight that through MacGyvering equipment, we are inherently susceptible to its namesake bias. In failing to recognize this bias, we could potentially be placing our patients at risk.

Institutional leadership is required to dismantle the (seemingly endless) amount of bureaucracy required to fund and stock appropriate clinical equipment, so that front-line healthcare practitioners have safe, proven equipment available when required. We do not suggest all workarounds are inherently poor. Nevertheless, we should be aware of their limitations and be willing to reflect on whether equipment deficits from poor planning or resource constraints are justifiable in modern healthcare settings. We need to recognize their limitations as we strive to promote creativity in our specialty, and in so doing, promote innovation while encouraging education that highlights cognitive biases, and addresses equipment deficits in a timely manner.

Conflicts of interest None declared.

Editorial responsibility This submission was handled by Dr. Philip M. Jones, Associate Editor, Canadian Journal of Anesthesia.

\section{References}

1. English Oxford Living Dictionaries. McGyver. Available from URL: https://en.oxforddictionaries.com/definition/macgyver (accessed March 2019).

2. Gosbee J, Gosbee LL. Usability evaluation in health care. In: Carayon P (Ed.). Handbook of Human Factors and Ergonomics in Health Care and Patient Safety, Second Edition. CRC Press; 2017: 543-56.

3. Macintosh RR, Pratt FB. Anaesthesia in war time. B Med J 1939; 2: 1077-9.

4. BMJ Obituary. Sir Robert Macintosh. BMJ 1989; 299: 851. Available from URL: https://www.bmj.com/content/299/6703/ 851 (accessed March 2019).

5. Brain AI. The laryngeal mask- a new concept in airway management. Br J Anaesth 1983; 55: 801-5.

6. Avery EC. The Leech airway: precursor to the modern supraglottic airway Can. J Anesth 2018; 65: 586-7.

7. Cohen $Y$, Rubenstein $R$, Berkenstadt $H$. A do-it-yourself videolaryngoscope for under $\$ 25$ - a solution in lower income countries? Anesth Analg 2016; 123(3S Suppl: 680-1 (abstract).

8. Norton MI, Mochon D, Ariely D. The IKEA effect: when labor leads to love. J Consum Psychol 2011; 22: 453-60.

9. Pandit JJ, Popat MT, Cook TM, et al. The difficult airway society 'ADEPT' guidance on selecting airway devices: the basis of a strategy for equipment evaluation. Anaesthesia 2011; 66: 726-37.

10. Vanderbilt $T$. The New Yorker. "Reverse innovation" could save lives. Why aren't we embracing it? February 2019. Available from URL: https://www.newyorker.com/science/elements/ reverse-innovation-could-save-lives-why-isnt-western-medicineembracing-it (accessed March 2019).

11. Boyce JR. Poor man's LMA: achieving adequate ventilation with a poor mask seal. Can J Anesth 2001; 48: 483-5.

12. Lalwani K. Poor man's LMA. Can J Anesth 2001; 48: 1047-8.

13. Duggan LV, Ballantyne Scott B, Law JA, Morris IR, Murphy MF, Griesdale DE. Transtracheal jet ventilation in the 'can't intubate can't oxygenate' emergency: a systematic review. Br J Anaesth 2016; 117(Suppl 1): i28-38.

14. Duggan LV, Lockhart SL, Romano KR, Weingart SD, Levitan $R M$, Brindley $P G$. Front-of-neck-airway meets front-of-neck simulation: improving cricothyroidotomy skills using a novel 
open-access three-dimensional model and the Airway App. Can J Anesth 2017; 64: 1079-81.

15. Duggan $L V$, Brindley $P G$, Law JA. Improving communication, teamwork and action during a "cannot intubate cannot oxygenate (CICO)" emergency: employing CICO as a cognitive aid mnemonic. Can J Anesth 2018; 65: 1087-92.

16. Ryder IG, Paoloni CC, Harle CC. Emergency transtracheal ventilation: assessment of breathing systems chosen by anaesthetists. Anaesthesia 1996; 51: 764-8.

17. Schwartz B. The Paradox of Choice: Why More is Less. NY: HarperCollins Publishers; 2004 .

18. Hamaekers A, Borg P, Enk D. The importance of flow and pressure release in emergency jet ventilation devices. Pediatr Anesth 2009; 19: 452-7.

19. Frerk $C$, Frampton $C$. Cricothyroidotomy; time for change. Anaesthesia 2006; 61: 921-3.

20. Health Canada. Safe Medical Devices in Canada. Available from URL: https://www.canada.ca/content/dam/hc-sc/migration/hc-sc/ dhp-mps/alt_formats/pdf/md-im/activit/fs-fi/meddevfs_matmedfdeng.pdf (accessed March 2019).

21. Star Editorial Board. The Star. More Oversight Needed from Health Canada on Medical Devices. Available from URL: https:// www.thestar.com/opinion/editorials/2018/11/26/more-oversightneeded-from-health-canada-on-medical-devices.html (accessed March 2019).

22. Ruskin KJ, Tung A. If I had some duct tape, I could fix that. Anesth Analg 2016; 123: 1072-3.

23. Greig PR, Higham HE, Darbyshire JL, Vincent C. Go/no-go decision in anaesthesia: wide variation in risk tolerance amoungst anaesthetists. Br J Anaesth 2017; 118: 740-6.

24. Dobson $G$, Chong $M$, Chow L, et al. Guidelines to the practice of anesthesia- revised edition 2018. Can J Anesth 2018; 65: 76-104.

Publisher's Note Springer Nature remains neutral with regard to jurisdictional claims in published maps and institutional affiliations. 